absence of any degenerative change seems to be related to the fact that normal recovery takes place when the scorbutic guinea pigs are given supplements of vitamin $\mathrm{C}$.

I wish to express my thanks to Dr. B. B. Sarkar and Mr. P. B. Sen of the Department of Physiology, University of Calcutta, for their kind help.

SACHChIDANANDA BANerJeE,

(Mitra Research Scholar).

School of Tropical Medicine,

Chittaranjan Avenue,

Calcutta.

Jan. 27.

Banerjee, S., NATURE, 152, 329 (1943).

\section{Growth-Inhibiting Action of Some Pure Substances}

Thrs preliminary report describes the results obtained with a certain class of growth-inhibitors. Since evidence exists that $H 11$ extract contains certain chemical compounds, it was decided to ascertain the inhibitory effects of some pure related substances upon the growth of the Twort carcinoma.

Tumour-bearing mice, averaging 25 gm. weight, were injected intraperitoneally, twice daily, with 0.5 c.c. of the solution to be tested. The surface areas of the tumours were calculated as the products of their diameters, and the group average determined. The inhibitory effect was calculated as the percentage difference between the average increases in size of the treated and the control mice.

Typical results obtained in comparable experiments are summarized in the accompanying table. Mice injected with certain chemicals, for example, anthraquinone, rapidly increased in weight during the course of the experiments, whereas the tumours were inhibited. Tests of substances toxic at higher concentrations, for example, the tannates, showed that, at lower concentrations, tumours were significantly inhibited, the host mice appearing completely unaffected.

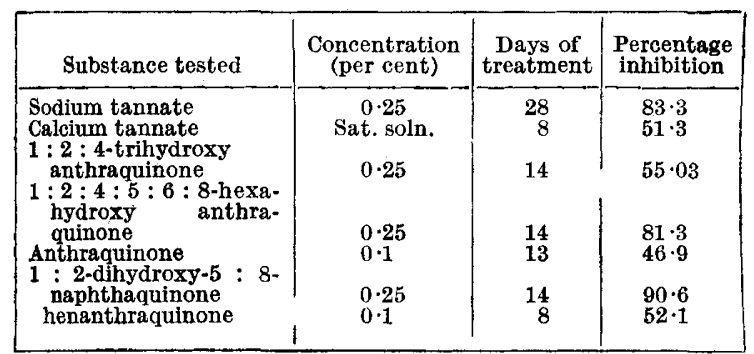

Badger et al. ${ }^{1}$ found that some quinone derivatives of carcinogenic hydrocarbons inhibited the growth of the Walker carcinoma 256, and Berenblum and Schoental ${ }^{2}$ came to similar conclusions. Other phenolic, aldehyde and quinone derivatives of cyclic hydrocarbons have been tested; the results will be described later.

All these compounds have the property of com. biming with proteins. Derivatives of vegetable tannins react with proteins because of their polyphenolic constitution, and quinone compounds through their characteristic radicals. The inhibitory effects of these otherwise dissimilar substances are probably directly due to this reaction. A much greater inhibition of tumour-growth than of body- growth was produced. This greater susceptibility to the action of the inhibitors shown by the malignant cells must presumably reside in their intrinsic differences.

Such differences may be accounted for by a provisional hypothesis concerning a modification of cytoplasmic organization in tumour cells. Needham ${ }^{3}$ has discussed the organization and differentiation of cells in terms of a cytoskeleton composed of protein fibrils. Wrinch ${ }^{4}$ holds a similar view. The hypothesis is that, in the malignant cell, the cytoskeletal components have lost the power of linking up with one another to form a three-dimensional lattice such as may exist in a normal cell.

Fully differentiated cells are unable to divide, but the 'disarticulated' cytoskeleton of a malignant cell, while providing the morphological basis of dedifferentiation, would not hinder division. As the abnormal fibrils would presumably lose the power of responding to the evocator substances which control differentiation, malignant cells would remain undifferentiated and show unregulated growth.

Mottram ${ }^{5}$ holds that malignancy results from cytoplasmic modification. The morphological differences between the cytoplasm of malignant and normal cells described by many workers are reviewed by Ludford ${ }^{6}$. The 'disarticulation' of cytoskeletal fibrils would result in such differences. The similarities between malignant cells and embryonic cells might also be explained in terms of the organization of the cytoskeleton.

On the cytoskeletal hypothesis, the various carcinogenic agents would induce malignancy by directly or indirectly modifying the cytoskeletal fibrils so that they no longer link up with one another. The premalignant period would be occupied by the accumulation of abnormal fibrils until their predominance prevents the formation of a normal 'articulated' cytoskeleton.

The mode of action of inhibitors with the property of tanning proteins would be to link up the discrete fibrils of a tumour cell to form a 'pseudo-cytoskeleton'; treated malignant cells would then become stabilized, 'non-malignant' cells, and would be much less able to reproduce themselves, with the result that the whole tumour would tend to regress. This effect of tanning agents on adult, healthy cells with normal cytoskeletons would be relatively insignificant. There may be a similar effect on the mitotic spindle and nucleus.

The cytoskeletal hypothesis furnishes a possible explanation of the site of action of tumour inhibitors which tan proteins and also of various phenomena associated with malignancy.

I am greatly indebted to Mr. J. H. Thompson, director of research of these Laboratories, for constant help and encouragement. My thanks are also due to Mr. C. R. B. Williamson for valuable technical assistance.

Department of Pathology,

A. K. PowelL.

Hosa Research Laboratories,

Sunbury-on-Thames, Middx.

${ }^{1}$ Badger, G. M., et al., Proc. Roy. Soc., B, 13, 130, 255 (1942).

Berenblum, I., and Schoental, R., Cancer Res., 3, 145 (1943).

"Needham, J., "Biochemistry and Morphogenesis" (Cambridge, 1942).

- Wrinch, D., NATURE, 150, 270 (1942).

"Mottram, J. C., "The Problem of Tumours" (London : H. K. Lewis and Co., 1942)

"Ludford, R. J., "Cytology of Cancer", pp. 252-259, in "Cytology and Cell Physiology", ed. G. Bourne (Oxford: Clarendon Press, 1942). 